\title{
Pediatric cancer: case studies illustrate mechanisms to address significant challenges
}

\author{
Andrew L. Kung ${ }^{1}$ and Elaine R. Mardis ${ }^{2}$ \\ ${ }^{1}$ Department of Pediatrics, MSK Kids, New York, New York 10065, USA; ${ }^{2}$ Institute for Genomic Medicine, \\ Nationwide Children's Hospital, Columbus, Ohio 43215, USA
}

The steady improvement in outcomes for children with cancer has in large part been achieved through risk-stratified therapy and maximum intensification of multimodality therapy for patients with poor prognostic disease. For most pediatric cancer types, further improvements in outcomes are unlikely to be achieved through further intensification of conventional treatment modalities and instead will require integration of more targeted therapies. Moreover, because a majority of survivors of childhood cancer have long-term toxicities attributable to the therapies used to treat disease, replacing conventional cytotoxic treatment modalities with more targeted approaches holds the promise of decreasing the toxicities incurred in the course of achieving a cure. Although very few cancer therapies are FDA-approved for pediatric cancer indications, recent approvals of targeted agents in a biomarker-based and tissue- and age-agnostic manner provides a framework for bringing new targeted therapies to impact children with cancer. The approval of larotrectinib for NTRK gene fusions, for example, provides a new therapeutic option for children with infantile fibrosarcoma driven by ETV6-NTRK3, without the need for clinical trials to prove efficacy specifically for this very rare indication. Likewise, the approval of pembrolizumab for all cancers with high microsatellite instability provides an FDA-approved option for the small number of children with DNA mismatch repair-deficient tumors. Comparative genomic studies have revealed some overlap in significantly mutated genes in both adult and pediatric cancers (Gröbner et al. 2018), which provides an impetus for using comprehensive cancer genomic characterization to identify genetic biomarkers predictive of response to targeted drugs in adult cancers for potential use in pediatric cancers sharing the same genetic biomarker.

Indeed, this special issue of Cold Spring Harbor Molecular Case Studies illustrates beauelaine.mardis@

nationwidechildrens.org

(c) 2019 Kung and Mardis This article is distributed under the terms of the Creative Commons Attribution-NonCommercial License, which permits reuse and redistribution, except for commercial purposes, provided that the original author and source are credited.

Published by Cold Spring Harbor Laboratory Press tifully, through the published reports herein, how the landscape of pediatric precision medicine is emerging along these lines. In particular, several reports illustrate rare cases of high mutational burden due to different underlying genetic contributors to cancer predisposition. These reports include two cases wherein constitutional mismatch repair deficiency (CMMRD) was found (see Momen et al., this issue, doi:10.1101/mcs.a004408; Yang et al., this issue, doi:10.1101/mcs.a003863). One patient presented with a germline pathogenic mutation in polymerase epsilon (POLE), which is not a canonical mismatch repair gene, and a second case presented with a single MSH6 mutation in the germline and both MSH6 and POLE somatic mutations. In several of these ultra-high mutation load tumors, the patients responded to the use of checkpoint blockade therapy, which mirrors the clinical trial results that led to FDA approval of anti PD-1 therapy for patients with any tissue site and mismatch repair deficiency (Le et al. 2017).

Several rare cancer types also are being reported in this issue, with identified drivers that doi:10.1101/mcs.a004788 
COLD SPRING HARBOR Molecular Case Studies
Special issue on pediatric cancers
Competing Interest Statement The authors have declared no competing interest. use. For those of us involved in the care of pediatric patients with these rare tumor types, this is familiar territory, and these results give us hope that the continuing use of NGS-based molecular characterization will reveal the clinical benefit of such approaches in the rare pediatric cancer setting. Two other reports outline support for new constitutional cancer predisposition genes in pediatric cancers, including GNAS in the setting of medulloblastoma (see Tokita et al., this issue, doi:10.1101/mcs.a004572) and RECQL4 in osteosarcomas (see Maciaszek et al., this issue, doi:10.1101/mcs.a004218). There also are important reports of novel gene alterations in pediatric cancers that have corresponding treatment responses.

Taken together, these manuscripts illustrate the rationale behind Cold Spring Harbor Molecular Case Studies_namely, to provide a mechanism for describing novel case studies that can inform the medical field, benefitting future patients and their care, and broaden our perceptions about the genetic nature of human disease and how to address it using novel therapeutic approaches, when applicable. As these efforts have grown internationally, it appears that the paradigmatic use of clinical trials, although still important for new drug approvals, may be superseded by sharing the data and outcomes from individual pediatric cancer patients whose genomic results led to the use of indicated therapeutic modalities. In pediatric cancer, as in all rare diseases, the dissemination of knowledge is critically important and obstacles to data sharing toward this end should be nonexistent if we are to fully benefit from the promise of genomics-guided precision medicine. Speaking to these truths, we are very pleased to offer two front half pieces in this special issue. One is provided by the researchers involved in The Treehouse Initiative at the University of California at Santa Cruz, who have developed an important new database and toolkit for the advanced analysis of pediatric cancer data, based on the notion of unhindered access to computational tools that accomplish this aim (see Sanders et al., this issue, doi:10.1101/mcs.a004317). A second Perspective from Sharon Plon and colleagues (see Lindsay et al., this issue, doi:10.1101/mcs.a004499). Provides an overview of a critically important effort at ClinGen to curate information about somatic cancer mutations and their appropriate, research-guided interpretation for use by the clinical diagnostics and research community. These, and other publicly available resources, will ultimately facilitate the democratization and access to genomics-based diagnoses and treatments that are required for every child to benefit.

\section{REFERENCES}

Gröbner SN, Worst BC, Weischenfeldt J, Buchhalter I, Kleinheinz K, Rudneva VA, Johann PD, Balasubramanian GP, Segura-Wang M, Brabetz S, et al. 2018. The landscape of genomic alterations across pediatric cancers. Nature 555: 321-327. doi:10.1038/nature25480

Le DT, Durham JN, Smith KN, Wang H, Bartlett BR, Aulakh LK, Lu S, Kemberling H, Wilt C, Luber BS, et al. 2017. Mismatch repair deficiency predicts response of solid tumors to PD-1 blockade. Science 357: 409-413. doi:10.1126/science.aan6733 


\section{COLD SPRING HARBOR Molecular Case Studies}

\section{Pediatric cancer: case studies illustrate mechanisms to address significant challenges}

Andrew L. Kung and Elaine R. Mardis

Cold Spring Harb Mol Case Stud 2019, 5: a004788

Access the most recent version at doi: $10.1101 / \mathrm{mcs} . a 004788$

References This article cites 2 articles, 1 of which can be accessed free at: http://molecularcasestudies.cshlp.org/content/5/5/a004788.full.html\#ref-list-1

License This article is distributed under the terms of the Creative Commons Attribution-NonCommercial License, which permits reuse and redistribution, except for commercial purposes, provided that the original author and source are credited.

Email Alerting Receive free email alerts when new articles cite this article - sign up in the box at the Service top right corner of the article or click here. 